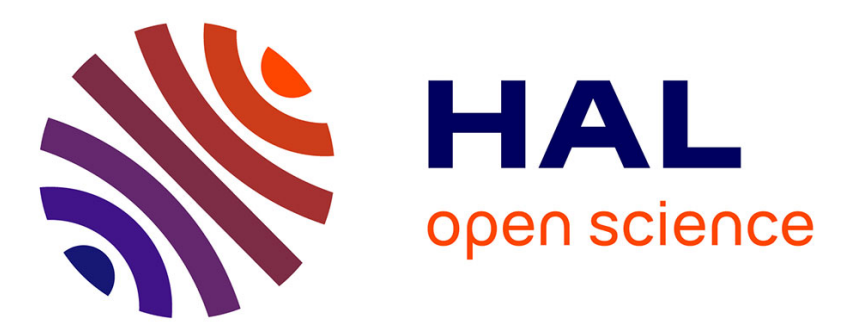

\title{
Long-term survival of patients with a history of venous thromboembolism
}

Sylvia Elisabeth Reitter, Thomas Waldhoer, Michaela Mayerhofer, Ernst Eigenbauer, Cihan Ay, Paul Alexander Kyrle, Ingrid Pabinger

\section{- To cite this version:}

Sylvia Elisabeth Reitter, Thomas Waldhoer, Michaela Mayerhofer, Ernst Eigenbauer, Cihan Ay, et al. Long-term survival of patients with a history of venous thromboembolism. Annals of Hematology, 2011, 90 (5), pp.585-594. 10.1007/s00277-011-1160-0 . hal-00612999

\section{HAL Id: hal-00612999 \\ https://hal.science/hal-00612999}

Submitted on 2 Aug 2011

HAL is a multi-disciplinary open access archive for the deposit and dissemination of scientific research documents, whether they are published or not. The documents may come from teaching and research institutions in France or abroad, or from public or private research centers.
L'archive ouverte pluridisciplinaire HAL, est destinée au dépôt et à la diffusion de documents scientifiques de niveau recherche, publiés ou non, émanant des établissements d'enseignement et de recherche français ou étrangers, des laboratoires publics ou privés. 


\section{Long-term Survival of Patients with a History of Venous Thromboembolism}

Reitter, Sylvia*1,; Waldhoer, Thomas ${ }^{\dagger} ; \quad$ Mayerhofer, Michaela*, Eigenbauer, Ernst ${ }^{\ddagger}$, Ay, Cihan ${ }^{\star}$, Kyrle, Paul Alexander ${ }^{\star}$, Pabinger, Ingrid ${ }^{\star}$

* Division of Haematology and Haemostaseology, Department of Medicine I, Medical University Vienna, Austria

${ }^{\dagger}$ Center for Public Health, Department of Epidemiology, Medical University Vienna, Austria

₹ Section of Medical Information Management und Imaging, Center for Medical Statistics, Infomatics and Intelligent Systems, Medical University Vienna, Austria

${ }^{1}$ Dr. Reitter is recipient of a Bayer Haemophilia Clinical Training Award

Correspondence: Prof. Dr. Ingrid Pabinger

Division of Haematology and Haemostaseology

Department of Medicine I, Medical University of Vienna

Waehringer Guertel 18-20

A-1090 Vienna, Austria

Phone number: +431404004448

Fax number: +43140400 4030

e-mail: ingrid.pabinger@meduniwien.ac.at 


\section{Summary}

Background: Limited data are available regarding long-term survival following venous thromboembolism (VTE). Objectives: Evaluating long-term survival by retrospective survival analysis in patients with a history of VTE, and comparing their survival with that of the general population. Patients/Methods: Patients with a history of VTE (min. 3 months after VTE) without cancer, who were referred to our department between 1994 and 2007, were included in the analysis. Information concerning mortality was available through the Austrian Central Death Register. The survival of patients was compared with that of the ageand gender-matched general Austrian population. Results: 3209 patients (mean age 46.2, range 14-89 years) were included. Median time interval between first VTE and inclusion was 14 months, median observation period was 6.6 years. During the considered time period 169 patients $(5.3 \%)$ died. The cumulative survival in patients was 0.97 and 0.87 after 5 and 10 years, men had a higher death rate than women, patients with idiopathic VTE had a less favourable survival than those with a triggering event. When patients were compared to the general population, the cumulative relative survival was 1.02 (95\% $\mathrm{Cl}$ 1.00-1.03). In none of the analysed subgroups (different sites of VTE, idiopathic vs. secondary VTE) a reduced cumulative relative survival was found. The relative survival of male patients even was slightly better, whereas that of women equalled the normal population. Conclusion: Our results indicate that after the initial phase VTE does not seem to impair long-term survival of patients with a history of VTE without cancer.

Key words: Venous thromboembolism, thrombosis, pulmonary embolism, survival, mortality 


\section{Introduction}

Venous thromboembolism (VTE) is a serious and often life-threatening disease, which presents as deep venous thrombosis and/or pulmonary embolism. Patients with symptomatic VTE have a considerable risk of recurrent VTE, which persists for many years[1].

In developed countries the incidence of VTE ranges between 1-2 per 1000 persons per year.[2, 3] The incidence of a first-time VTE increases exponentially with age: ranging from a very low rate $(0.05$ per 1000 persons per year) among children aged 15 years to a rate of 5 per 1000 persons per year among individuals older than 80 years of age.[4]

Two-thirds of first-time episodes of deep venous thrombosis (DVT) occur in connection with external factors, such as surgery, immobilization or trauma[5]. In women, pregnancy, puerperium and oral contraceptives $(\mathrm{OC})$ represent further risk factors. In addition, demographic risk factors for first VTE as well as for recurrent events are known, such as advanced age[6, 7], obesity[8], cancer and male sex[4]. Some clinical factors are known to increase the risk of recurrence, e.g. first manifestation as pulmonary embolism (PE)[7].

Estimates on mortality after VTE vary considerably. Short-term mortality (30 and 90 days after VTE) varies from less than 3 to $5 \%$ for DVT and from 6 to $23 \%$ for PE. Less is known about long-term survival rates. Long-term survival rates reported thus far vary from 61 to $75 \%$.[2, 9]. Factors influencing the survival rate in thrombosis patients are as follows: time since onset of thrombosis[10], age[11], idiopathic thrombosis[10, 11] and, most importantly, cancer[10, 12]. Studies comparing survival rates of patients with a history of thrombosis to the survival of the general population are scarce and show considerable variability[10, 12, 13].

The aim of our study was to investigate the long-term survival rate in patients with a history of DVT and/or PE who were referred to our department for coagulation testing, and to evaluate the relative survival of these patients in comparison to the general Austrian population. We also assessed long-term 
survival according to the etiology of VTE (spontaneous or following a triggering event) and to the site of thrombosis.

\section{Patients and methods}

\section{Patients}

All patients with a history of VTE who were investigated at our out-patient department for routine thrombophilia testing between September 1, 1994 and December 31, 2007, were included in the study. All VTE events had occurred at least three months prior to their first visit at our department and not earlier than 1980. VTE had always been confirmed by objective methods, such as phlebography, plethysmography, duplex ultrasonography, perfusion ventilation lung scan or computed tomography. We included neither patients with active cancer at time of referral, nor patients with asymptomatic PE, nor patients with an isolated visceral vein thrombosis (e.g. thrombosis of the Vv. mesentericae or V. portae) in our study. The minimum age of our patients at time of inclusion was 14 years.

Overall, 4958 patients with a history of DVT or PE were seen at our outpatient department within the study period. 1749 patients were not included in the analysis due to the following reasons: 297 were not eligible due to active cancer, 936 due to acute VTE (VTE $<3$ months ago), 214 because their first venous thromboembolic event occurred before 1980, 40 due to isolated visceral thrombosis, 262 because their VTE was diagnosed only clinically or PE was asymptomatic.

Regarding treatment definitions, short-term oral anticoagulation (OAC) was defined as treatment with vitamin-K-antagonists after the first DVT or PE for up to 6 months after the event, long-term treatment was defined as treatment beyond 18 months after the initial DVT or PE.

All VTEs were classified as secondary or idiopathic. An event was regarded as secondary, when at least one of the following factors was present: trauma, surgery, marked immobility (e.g. cast, prolonged bed confinement due to an acute illness, long-distance travel), pregnancy (peri- and postpartal) or Caesar- 
ean section within the last 6 weeks or use of oral contraceptives. An event was classified as idiopathic when none of the above-mentioned factors was recorded in the patient history.

\section{Methods}

A retrospective survival analysis of the above-mentioned patients for the period September 1, 1994 to December 31, 2008 was performed. The present study was approved by the ethics committee of the Medical University of Vienna.

Patient data was derived from the detailed and structured medical records made at each patient's visit to our outpatient department. A physician reviewed all medical records in order to confirm the cases. Patients for whom the information on the duration of OAC following their first VTE was incomplete were contacted by telephone or mail to obtain the missing information.

In addition to patient file information, data on the mortality of our patients was obtained from the Austrian Central Death Register, which is recorded, maintained and updated by Statistics Austria[14]. Causes of death were coded according to the International Classification of Diseases (ICD versions 9 and 10, respectively). Data on the overall mortality of the general Austrian population was also obtained from Statistics Austria.

\section{$\underline{\text { Statistical analysis }}$}

The survival of our patients was estimated and summarized using the Kaplan-Meier method[15].

After adjustment for age, gender and calendar period, the patient survival rates were compared with those of the general Austrian population using relative survival methods[16]. Calculations were made in SAS and SAS macros provided by Dickman et al.[17].

Regarding the delineation of cumulative survival and cumulative relative survival rates, the overall considered time period covers 14 years. However, we have chosen a period of only 10 years for calculating the given cumulative (relative) survival rates and for the p-values, because only few events occurred 
thereafter, and the confidence intervals beyond this point were wide, making a clear interpretation difficult.

\section{Results}

\section{$\underline{\text { Patient characteristics }}$}

In total, 3209 patients were included in the present study, of whom $40 \%$ were men $(n=1280)$. The mean age of our patients at time of inclusion, i.e. when visiting our department for coagulation testing, was 46.2 years (range $14-89$ years). Table 1 displays the characteristics of all included patients.

Median time interval between the first DVT or PE and the investigation at our department was 14 months (interquartile range (IQR) $6-71$ months). For $97 \%$ of all patients ( $n=3101$ ) information was available regarding duration of anticoagulation following their initial VTE. Of these patients, 1682 (52.4\%) had short-term anticoagulation (<6 months) with vitamin-K-antagonists or low molecular weight heparin, 881 (27.5\%) had anticoagulation between 6 and 18 months and only 538 patients (16.8\%) had long-term anticoagulation with vitamin-K-antagonists for $>18$ months after the first DVT or PE. At the time of study inclusion, 1178 patients (36.7\%) had OAC therapy.

The median follow-up time between the first visit at our clinic for routine coagulation screening and $12 / 2008$ or death was 6.6 years.

\section{Survival in the patient population}

During the entire analysis period, i.e. between September 1, 1994 and December 31, 2008, a total of 169 patients died, of whom $47 \%(n=79)$ were men. Regarding the specific causes of death, see table 2. The mean age at death was 69 years (IQR $59-81$ years).

Regarding death due to VTE, the eight cases of VTE were definite PE in six cases and possible PE (sudden death of undetermined cause) in two cases. The six cases of bleeding were intra-cerebral 
haemorrhages in three cases, and bleeding of an ulcus duodeni, coagulopathy of unknown origin and rupture of an aortic aneurysm in one case each.

Myocardial infarction, cardiac insufficiency, atherosclerosis, cardiomyopathy and hypertensive heart disease were grouped to "cardiovascular causes / heart failure".

"Pulmonary" causes of death (apart from PE) were chronic obstructive pulmonary disease and emphysema. "Renal" causes were (chronic) renal insufficiency and nephritic syndrome.

Cumulative survival rates are depicted in Figures 1a - 1d. The cumulative survival in the total study population was 0.97 after 5 years and 0.87 after 10 years. The cumulative survival rate of men indicated a significant decrease when compared to that of women $(p=0.01)$, the probability of survival in men and women was 0.96 and 0.97 after 5 years and 0.91 and 0.93 after 10 years. Regarding triggering factors, the lowest survival was found in patients with spontaneous VTE (cumulative survival after 10 years = $0.88,95 \% \mathrm{Cl} 0.85-0.90)$, as opposed to $0.94(95 \% \mathrm{Cl} 0.91-0.96)$ in patients with VTE following trauma or surgery; in those with VTE following another triggering event it was $0.94(95 \% \mathrm{Cl} 0.88-0.97)$, whereas in patients under oral contraceptives or hormone therapy or in patients with VTE during pregnancy or peripartal the cumulative survival was $0.99(95 \% \mathrm{Cl} 0.96-0.99)$.

With respect to the site of VTE, the lowest cumulative survival rates were found in patients with PE (cumulative survival $=0.91$ after 10 years, $95 \% \mathrm{Cl} 0.86-0.95)$ and with VTE in other localisations with or without DVT of the leg (cumulative survival $=0.89,95 \% \mathrm{Cl} 0.85-0.93)$, while it was $0.93(95 \% \mathrm{Cl} 0.91$ - 0.94) in patients with DVT of the leg only and $0.93(95 \% \mathrm{Cl} 0.86-0.97)$ in those with a combination of PE and DVT of the leg or VTE in other localisations.

Duration of anticoagulation (long-term vs. short-term) did not have an influence on the cumulative survival rates $(p=0.96)$.

\section{Relative cumulative survival}


The cumulative relative survival of all our patients in comparison to the general Austrian population was 1.02 (95\% confidence interval $(\mathrm{Cl}) 1.00-1.03)$. When stratified by gender, the cumulative relative survival of female patients equalled that of the general population with a cumulative relative survival rate of $1.00(95 \% \mathrm{Cl} 0.98-1.01)$, whereas in male patients the cumulative relative survival rate was 1.05 $(95 \% \mathrm{Cl} 1.03-1.08)$.

With respect to triggering factors, the cumulative relative survival of patients with spontaneous VTE was 1.02 (95\% Cl $0.99-1.04$, figure $2 a)$. In women whose thrombosis was triggered either by oral contraceptives or hormone replacement therapy or pregnancy, a cumulative relative survival rate of 0.97 (95\% Cl $0.97-1.01$, Figure 2b) was found. In patients with VTE following trauma or surgery, the cumulative relative survival was $1.03(95 \% \mathrm{Cl} 1.00-1.05$, figure $2 \mathrm{c})$. Patients with other triggering events had a relative survival that was not significantly different from the general population's $(1.04,95 \% \mathrm{Cl} 0.99-$ 1.06, Figure 2d).

In a further analysis the relative survival of patients presenting with different sites of venous thromboembolism was evaluated (see figure 3). Relative survival in patients with PE was 1.03 (95\% Cl $0.98-1.06$, Figure 3a), in those with DVT of the leg it was 1.02 (95\% Cl $1.00-1.04)$, Figure 3b), in patients with combined PE and DVT of the leg or VTE of another localisation it was $1.01(95 \% \mathrm{Cl} 0.94-1.05$, Figure $3 c$ ), and in the group with other localisations it was 1.01 (95 \% Cl $0.96-1.05$, Figure 3d).

\section{Discussion}

We aimed to evaluate long-term survival following an episode of VTE. Our data are based on a cohort of more than 3200 patients, in whom survival after an initial episode of VTE was investigated over a long period of time. Our data show that long-term survival of patients without cancer, who survived the acute phase of VTE, is comparable to survival rates of the general Austrian population.

As expected, the cumulative survival rate of men was lower compared to women, and patients with idiopathic VTE had a less favourable prognosis for survival than those with a triggering event. When pa8 
tients were compared to the general population, in none of the analysed subgroups (different sites of VTE, idiopathic vs. secondary VTE) a reduced cumulative relative survival rate was found. However, in comparison to the general population it turned out that men even had a tendency towards a longer relative survival, whereas the cumulative relative survival in women equalled that of the general Austrian female population.

Plausible explanations for the tendency towards a better survival in our group of male patients compared to the average Austrian male population might be a change of lifestyle and more emphasis on healthconsciousness. The acute event of VTE might stimulate health-consciousness and the awareness of illness, thereby leading to a change of lifestyle, e.g. cessation of smoking, change in diet, weight reduction, as well as to more frequent medical check-ups. This may have a larger impact in men, because women have in general been found to be more health-conscious, also consulting their physician for medical attention and undergoing routine check-ups more regularly. This fact was documented in the Austrian micro census that revealed that women of all age groups consult general practitioners more often than men.[18] A study in Sweden convincingly showed that changes in lifestyle, such as those mentioned above, influence fibrinolytic parameters in patients with VTE and even lower the recurrence rates.[19] Such life-style changes might have an even stronger impact on other frequent diseases, such as arteriosclerotic heart disease or cancer. We presume that a higher attention to symptoms associated with life-threatening diseases and changes in life style could reasonably explain this rather unexpected improved long-term survival in our male patient cohort.

Recently, Naess et al.[10] performed a population-based study in Norway, investigating the mortality of patients with VTE. They found that in patients with VTE and without cancer the mortality rate gradually approached that of the general population during the first year of the event. The mortality rate was, as expected, higher in the acute phase following VTE, i.e. during the first months. The reported overall high long-term mortality rate was found to be mainly related to cancer. 
Another recent study published by Flinterman et al.[12] reflects our findings as well. When excluding patients with malignancy, the standard mortality ratio (SMR) was 1.1 for all patients; 0.5 for men and 4.7 for women. The median follow-up period was three years. This study was conducted among patients with a venous thrombosis of the upper extremity, so these data are not directly comparable with the results from our study; nonetheless, they point into the same direction. Although the location of VTE differs from our cohort, the comparison with the general population showed a similar survival of the patient cohort and, interestingly, there was also a notable difference between the SMR of men versus women, in the way that men had a much better SMR than women.

A population-based study performed by Heit et al.[13, 20] in Olmsted County among 2218 patients with DVT or PE compared the mortality of patients with VTE to the mortality among the general population. In this survey, the median follow-up time was 6.6 years. Patients who survived the first year had a survival notably worse than expected; namely, $71.6 \%$ instead of the expected $80.3 \%$ after eight years. The cohort studied by Heit et al. had their first VTE between 1966 and 1990. It has to be mentioned that diagnosis and treatment of VTE have been considerably improved in the last 2-3 decades. In the acute phase a relatively high percentage of deaths (37\%) occurred upon diagnosis or VTE was even diagnosed post mortem. In these respects this study differs from ours, as it was not our aim to study the death rate in the acute phase, neither did we include data from post-mortem examinations of the population. Furthermore, in contrast to our study, patients with cancer were also included in the study in Olmsted County. These facts might well account for the difference between the study by Heit et al. and the present study.

Douketis et al.[11] evaluated the survival rate in two cohorts of patients (one Italian and one Canadian, in total 2052 patients), data of these cohorts were combined. Similar to our results, patients with spontaneous thrombosis had a worse survival, whereas there was not much difference in survival with regard to the site of the venous thromboembolic event. The overall reported mortality rate of $14 \%$ during an average follow-up period of 54 months after discontinuation of anticoagulant therapy is higher than in our cohort. However, patients included in this study in mean were 14 years older than the patients of our 
cohort (62 versus 46 years), which most likely accounts for the higher mortality rate. Unfortunately, in this study neither a comparison between male and female patients nor a comparison to the general population was made. Especially the latter would have been of major importance in order to compare the reported death rate to our study.

Another study by Schulman et al.[6] showed a death rate of $28.5 \%$ after 10 years of follow-up, which was $43 \%$ higher than expected from population data. Patients included in this study were older than those in our study (mean age above 60 years) and the acute phase following VTE was also included in the assessment.

In a study by Ridker et al.[21], which did not include the acute phase following VTE, but evaluated the survival of patients following a median of 6.5 years of full-dose anticoagulation therapy, a death rate of $2.4 \%$ after a mean follow-up of 2.1 years was observed. This is quite comparable to our mortality rate of around $4 \%$ after five years when considering the longer follow-up period in our cohort. Also, the median age of 53 years for patients included in the study by Ridker et al. is close to the median age in our cohort. Ridker et al. only included patients with an idiopathic VTE, which was not the case in our study. Therefore, we would actually expect an overall lower risk profile in our cohort. No direct comparison with the general population was performed in this study.

White et al.[22] retrospectively reviewed data of more than 3400 patients below the age of 55 after an initial episode of idiopathic PE. Recurrence and mortality rates were determined over a mean period of 3.2 years. During the follow-up period, $3.4 \%$ of the patients died. This corresponds to the death rate of $5.3 \%$ found in our patient cohort.

Our study has several limitations. Certainly, the most important limitation is the retrospective design. However, the fact that we included all consecutive patients who visited our department for routine thrombophilia testing during a given time period, can, on the other hand, be considered a special feature of our study. Furthermore, we are unable to draw any conclusions concerning short-term survival, as our study does not cover the acute phase following VTE. Anyway, this was not the objective of our study. It 
is probable that some deaths may not have been recorded due to patients' relocation abroad. However, the Austrian population relocates only rarely, and the Austrian Death Register covers the whole nation. Furthermore, if some deaths have been overlooked due to this reason, this would also have affected the female group. Therefore, it can be concluded that the relocation abroad does not account for the difference noticed between men and women. The fact that we did not include patients with malignancies in our study, of course, also accounts for a better survival. However, this effect might rather be expected in the first couple of years of follow-up, whereas differences in mortality in comparison with the general population were observed after 5 years of observation. Cancer was the most frequent cause of death in our patient population, reflecting the causes of death that can be expected in the age group of patients after 50 years of age. We would like to point out that our entire patient cohort consists of outpatients. Therefore, there might be some selection bias. Chronically ill or bed-ridden patients might not have been included to a representative extent. This, of course, is also reflected by the relatively young age at the time of inclusion (mean 46.2 years).

In conclusion, our results indicate that after the critical initial period, VTE does not seem to impair longterm survival of outpatients without active malignancy. This is most probably due to the current improved diagnostic and treatment modalities of recurrent VTE, which are most effective and safe. When deciding on long-term anticoagulation, the risk of fatal bleeding should be thoroughly balanced against the risk of fatal recurrent VTE, which - even though it might definitively occur, as also seen in our patient population - yet seems to have no major impact on the overall survival of the cohort of patients with a history of VTE in comparison to that of the general population after overcoming the critical initial time period. 


\section{AUTHOR CONTRIBUTIONS}

Study concept and design: Pabinger, Reitter

Acquisition of data: Reitter, Mayerhofer, Eigenbauer, Ay

Analysis and interpretation of data: Pabinger, Kyrle, Ay, Reitter

Patient inclusion and management: Pabinger, Kyrle

Drafting of the manuscript: Reitter, Pabinger

Critical revision of the manuscript for important intellectual content: Kyrle, Ay, Reitter, Waldhör, Pabinger

Statistical analysis: Waldhör, Reitter

Obtained funding: n.a.

Study supervisor: Pabinger

\section{Acknowledgements}

We thank Tanja Altreiter, MA (Clinical Division of Haematology and Haemostaseology, Department of Medicine I, Medical University Vienna) for proof-reading of the manuscript.

\section{Disclosure of Conflicts of Interests}

The authors state that they have no conflicts of interest. 


\section{Reference List}

[1] Palareti G, Cosmi B. Predicting the risk of recurrence of venous thromboembolism. Curr Opin Hematol 2004;11:192-7.

[2] Anderson FA, Jr., Wheeler HB, Goldberg RJ, Hosmer DW, Patwardhan NA, Jovanovic B, Forcier A, Dalen JE. A population-based perspective of the hospital incidence and case-fatality rates of deep vein thrombosis and pulmonary embolism. The Worcester DVT Study. Arch Intern Med 1991;151:933-8.

[3] Nordstrom M, Lindblad B, Bergqvist D, Kjellstrom T. A prospective study of the incidence of deep-vein thrombosis within a defined urban population. J Intern Med 1992;232:155-60.

[4] Kyrle PA, Minar E, Bialonczyk C, Hirschl M, Weltermann A, Eichinger S. The risk of recurrent venous thromboembolism in men and women. N Engl J Med 2004;350:2558-63.

[5] Kyrle PA, Eichinger S. Deep vein thrombosis. Lancet 2005;365:1163-74.

[6] Schulman S, Lindmarker P, Holmstrom M, Larfars G, Carlsson A, Nicol P, Svensson E, Ljungberg B, Viering S, Nordlander S, Leijd B, Jahed K, Hjorth M, Linder O, Beckman M. Post-thrombotic syndrome, recurrence, and death 10 years after the first episode of venous thromboembolism treated with warfarin for 6 weeks or 6 months. J Thromb Haemost 2006;4:734-42.

[7] Eichinger S, Weltermann A, Minar E, Stain M, Schonauer V, Schneider B, Kyrle PA. Symptomatic pulmonary embolism and the risk of recurrent venous thromboembolism. Arch Intern Med 2004;164:92-6.

[8] Garcia-Fuster MJ, Forner MJ, Fernandez C, Gil J, Vaya A, Maldonado L. Long-term prospective study of recurrent venous thromboembolism in patients younger than 50 years. Pathophysiol Haemost Thromb 2005;34:6-12.

[9] Kniffin WD, Jr., Baron JA, Barrett J, Birkmeyer JD, Anderson FA, Jr. The epidemiology of diagnosed pulmonary embolism and deep venous thrombosis in the elderly. Arch Intern Med 1994;154:861-6.

[10] Naess IA, Christiansen SC, Romundstad P, Cannegieter SC, Rosendaal FR, Hammerstrom J. Incidence and mortality of venous thrombosis: a population-based study. J Thromb Haemost 2007;5:692-9.

[11] Douketis JD, Gu CS, Schulman S, Ghirarduzzi A, Pengo V, Prandoni P. The risk for fatal pulmonary embolism after discontinuing anticoagulant therapy for venous thromboembolism. Ann Intern Med 2007;147:76674.

[12] Flinterman LE, van H, V, Rosendaal FR, Doggen CJ. Recurrent thrombosis and survival after a first venous thrombosis of the upper extremity. Circulation 2008;118:1366-72.

[13] Heit JA, Silverstein MD, Mohr DN, Petterson TM, O'Fallon WM, Melton LJ, III. Predictors of survival after deep vein thrombosis and pulmonary embolism: a population-based, cohort study. Arch Intern Med 1999;159:445-53.

[14] Statistics Austria. http://www.statistik.at/web en. 2010. Ref Type: Internet Communication

[15] Kaplan EL MP. Nonparametric-estimation from incomplete observations. Journal of the American Statistical Association 1958;53:457-81.

[16] Dickman PW, Sloggett A, Hills M, Hakulinen T. Regression models for relative survival. Stat Med 2004;23:51-64.

[17] Estimating and modelling relative survival using SAS. Internet . 2010. 1-12-2009.

Ref Type: Internet Communication 
[18] Austrian Micro Census. http://www.statistik.at/web en/statistics/health/health care/outpatient care/index.html. 20-6-2010.

Ref Type: Internet Communication

[19] Schulman S, Lindmarker P, Johnsson H. Influence of changes in lifestyle on fibrinolytic parameters and recurrence rate in patients with venous thromboembolism. Blood Coagul Fibrinolysis 1995;6:311-6.

[20] Heit JA, Silverstein MD, Mohr DN, Petterson TM, Lohse CM, O'Fallon WM, Melton LJ, III. The epidemiology of venous thromboembolism in the community. Thromb Haemost 2001;86:452-63.

[21] Ridker PM, Goldhaber SZ, Danielson E, Rosenberg Y, Eby CS, Deitcher SR, Cushman M, Moll S, Kessler CM, Elliott CG, Paulson R, Wong T, Bauer KA, Schwartz BA, Miletich JP, Bounameaux H, Glynn RJ, Ridker PM, Glynn RJ, Danielson EM, Bates D, Christen W, DeFonce P, Griffin W, Jackson F, Murray A, Taylor K, Johnson K, McKenna K, Pierre J, Holman B, Dessources F, Quinn P, Laurinaitis T, MacFadyen J, Eby C, Miletich JP, Porche-Sorbet R, Goldhaber SZ, Morrison RB, MacDougall RC, Morrison RM, Lamas G, Bailey K, Gersh B, Pellegrino E, Rick M, Vaughan D, Rosenberg Y, Goldhaber SZ, Morrison RB, MacDougall RC, Morrison RM, Deitcher SR, Olin J, Sulzer S, Cushman M, Cohen R, Moll S, Jones S, Kessler CM, Lee A, Elliott CG, Kitterman N, Jafri S, Wulbrecht N, Bauer K, Mahony M, Paulson R, Vold D, Wong T, Erickson-Nesmith S, Bounameaux H, de Lucia S, Chagnon I, Schwartz B, Thackery R, Gates N, Nguyen P, Paris S, LeCours B, Oliver M, Hodapp K, Grad G, Bank B, Rindels J, Leano C, Haire W, O'Grady D, Schneider J, Key N, Christie B, Blostein M, Strulovitch C, Usedom J, Oskins D, Eby C, Lee V, Heuerman S, Kerins D, Roberts B, White R, Castro E, Riddle E, Ingram M, Becker RC, Emery C, Wong L, Dent S, Comp P, Havarda D, Galichia JP, Terry L, Waldren S, Hambleton J, Pineo G, Hull R, Sheldon J, Tsapatsaris N, Woodhead G, Mann M, Welsh C, Schoch T, Goldsmith J, Anthony T, Walters J, Caprini J, Maher ML, Medica K, Rabbitt S, Finocchio J, Keaton K, Lee H, McLean S, Barban K, Mohler E, Medenilla E, Wolfe M, deLemos A, Rubenfire M, McDevitt S, Housholder S, Siegel JE, Bradley B, Brophy M, Reilly C, Brown E, Valeria A, Rodriguez L, Kumar A, Pekron J, Wagner J, Richart J, Jones J, Weber V, Fellin C, Sim J, Graham M, Sutton D, Tezcan H, Herbst S, Waldrum M, Meadows T, Carlson W, WelchCostantino M, Gosset J, Nonnweiler J, Kumar A, Green K, Tapson V, Krichman A, Yeo E, BorossHarmer S. Long-term, low-intensity warfarin therapy for the prevention of recurrent venous thromboembolism. New England Journal of Medicine 2003;348:1425-34.

[22] White RH, Zhou H, Murin S. Death due to recurrent thromboembolism among younger healthier individuals hospitalized for idiopathic pulmonary embolism. Thromb Haemost 2008;99:683-90.

Figure Legends:

Figure 1: Cumulative survival

Figure 2: Cumulative relative survival and triggering events

Figure 3: Cumulative relative survival figures and localisation 
Table $1 \quad$ Patient characteristics

\begin{tabular}{lccc} 
Site of VTE & $\begin{array}{c}\text { Patient number/ } \\
\text { Total patient } \\
\text { number }\end{array}$ & Percentage & $\%$ men \\
\hline DVT leg & $1893 / 3209$ & $59 \%$ & $40 \%$ \\
PE without detectable DVT & $548 / 3209$ & $17.1 \%$ & $38 \%$ \\
PE and DVT leg or thrombosis in another location & $491 / 3209$ & $15.3 \%$ & $44.8 \%$ \\
Others (thrombosis of the arm, vena cava, vena & $277 / 3209$ & $8.6 \%$ & $34.3 \%$ \\
jugularis, cerebral) \pm DVT leg & $1513 / 3209$ & $47.1 \%$ & $54.4 \%$ \\
\hline Spontaneous VTE & & & \\
\hline Triggering event & $816 / 3209$ & $25.4 \%$ & $41.5 \%$ \\
\hline Surgery / trauma & $592 / 3209$ & $18.4 \%$ & $0.2 \%$ \\
$\begin{array}{l}\text { Pregnancy / puerperium / Caesarean section / } \\
\text { abortion / oral contraceptives / hormone therapy }\end{array}$ & \multicolumn{2}{c}{$9 \%$} & $40.6 \%$ \\
\hline Others (immobilisation, acute illness) & $288 / 3209$ & $31.2 \%$ & $36.2 \%$
\end{tabular}

Abbreviations: DVT - deep vein thrombosis; PE - pulmonary embolism 


\section{Table 2 Causes of death}

Cause of death

Number of patients (\%)

(Total number $\mathrm{n}=169$ )

VTE, thereof:

$\sum 8(4.7 \%)$

Definite PE

$6(3.6 \%)$

Possible PE

$2(1.2 \%)$

Bleedings

$6(3.6 \%)$

Other causes:

Cardiovascular causes/heart failure

$46(27.2 \%)$

Malignancies

$58(34.3 \%)$

Trauma / accident

$12(7.1 \%)$

Addiction / suicide

$5(3 \%)$

Others (e.g. pulmonary, renal causes, infection, long-term consequences of diabetes mellitus)

$34(20.1 \%)$ 